\section{CBCT Post-Processing Tools to Manage the Progression of Invasive Cervical Resorption: A Case Report}

Karla de Faria Vasconcelos ${ }^{1}$, Sergio Lins de-Azevedo-Vaz², Deborah Queiroz Freitas $^{1}$, Francisco Haiter-Neto ${ }^{1}$

This case report aimed to highlight the usefulness of cone beam computed tomography (CBCT) and its post-processing tools for the diagnosis, follow-up and treatment planning of invasive cervical resorption (ICR). A 16-year-old female patient was referred for periapical radiographic examination, which revealed an irregular but well demarcated radiolucency in the mandibular right central incisor. In addition, CBCT scanning was performed to distinguish between ICR and internal root resorption. After the diagnosis of $\mathrm{ICR}$, the patient was advised to return shortly but did so only six years later. At that time, another CBCT scan was performed and CBCT registration and subtraction were done to document lesion progress. These imaging tools were able to show lesion progress and extent clearly and were fundamental for differential diagnosis and treatment decision.

\author{
'Department of Oral Diagnosis, \\ Division of Oral Radiology, \\ Piracicaba Dental School, \\ UNICAMP - Universidade Estadual \\ de Campinas, Piracicaba, SP, Brazil \\ ${ }^{2}$ Department of Clinical \\ Dentistry, Dental School, UFES - \\ Universidade Federal do Espírito \\ Santo, Vitória, ES, Brazil
}

Correspondence: Karla de Faria Vasconcelos, Avenida Limeira, 901, 13414-903 Piracicaba, SP, Brazil. Tel: +55-19-98294-6677. e-mail: karlafav13@gmail.com

Key Words: cone beam computed tomography, dental radiography, diagnosis, root resorption.

\section{Introduction}

Invasive cervical resorption (ICR) is an uncommon type of external dental root destruction characterized by loss of dentin or cementum due to osteoclastic resorption (1). In most cases, a single tooth is involved, but multiple tooth involvement has also been reported (2). This lesion was defined by Tonstad (3) as "a localized resorptive process that starts on the surface of the root below the epithelial attachment and the coronal aspect of the supporting alveolar process, namely the zone of the connective tissue attachment" (3).

Normally there are no obvious clinical signs and the condition is often diagnosed by chance during radiographic examination acquired for other purposes. Heithersay (4) has described this kind of external resorption at length and divided it into four classes. Class 1 is characterized by a small invasive resorptive lesion near the cervical area with shallow penetration into dentin. Class 2 appears as a welldefined resorptive lesion close to the pulp chamber with little to no extension into radicular dentin. Class 3 consists of a resorptive defect involving the coronal third of the root; and Class 4 appears as a resorptive defect extending beyond the cervical third of the root (4).

External and internal root resorption may have very similar features in conventional radiographs (5). Serial radiographic exposures using horizontal tube shifting methods such as Clark's help distinguishing internal resorption images from external ones. However, since conventional radiographs are two-dimensional images, proper representation of all relevant anatomic aspects cannot be assured (6). Therefore, differential diagnosis between internal/external resorption and ICR by conventional radiography can be problematic.

Cone beam computed tomography (CBCT) has been extensively explored as a tool for diagnosis, treatment planning and follow-up in Dentistry, mainly in Endodontics. However, the efficacy, benefits and risk of this technique should be taken into account. In this way, it is essential that selection of dental CBCT is based on the patient's history and clinical examination. The major advantage of CBCT over conventional radiography is its threedimensional geometric accuracy (7-9). The axial and sagittal reconstructions are of particular value and the new tools available in many dedicated CBCT softwares can improve diagnostic and follow-up data gathering.

Registration tools that allow superposition of DICOM data, as well as the possibility to superpose and subtract images are highly interesting for dental radiologists and clinicians. The digital subtraction technique consists in subtracting one image pixel values from another, resulting in a homogeneous grey image. Changes in the follow-up may appear as dark or brighter areas and they mean loss and gain of mineral tissues, respectively (10).

This paper reports a case in which $\mathrm{CBCT}$, along with post-scanning registration and subtraction tools, was useful for establishing the diagnosis of ICR, while also aiding in treatment planning and follow-up.

\section{Case Report}

A 16-year-old female patient was referred to the Piracicaba Dental School's Oral Radiology Center, Brazil for periapical radiographic examination, which 
rvealed an irregular yet well-limited radiolucency at the cementoenamel junction of the right mandibular central incisor (Fig. 1). Her medical history was unremarkable, but she had a history of orthodontic treatment. There was no

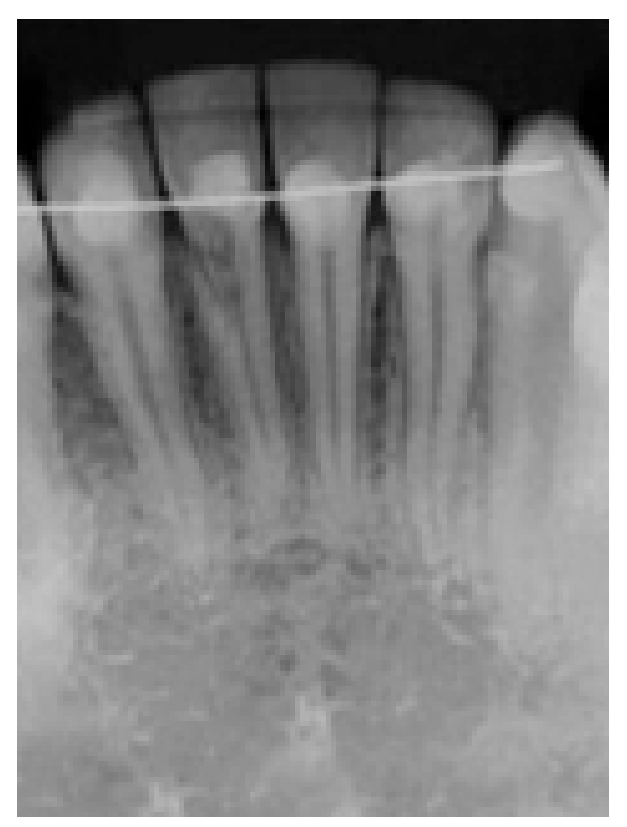

Figure 1. Periapical radiography showing an irregular but well-limited radiolucency at the cementoenamel junction of the mandibular right central incisor. discoloration of the crown or tenderness upon percussion and the tooth responded normally to pulp vitality tests. The interdental alveolar crest and the periodontal space did not show any abnormalities. An interim diagnosis of ICR or internal root resorption was made. Before definitive diagnosis, CBCT images were acquired in order to determine the extent of the lesion and whether it reached the dental pulp.

The i-CAT Classic device (Imaging Sciences International, Hatfield, PA, USA) was used for (BCT image acquisition, with exposure parameters set to $120 \mathrm{kV}, 37.07$ $\mathrm{mA}, 26.9 \mathrm{~s}, 0.25 \mathrm{~mm}$ voxel size and a $6 \mathrm{~cm} \times 16 \mathrm{~cm}$ field of view. Evaluation of the axial, coronal and sagittal reconstructions showed an irregular destruction in the vestibular, distal and lingual walls of the mandibular right central incisor's root and the root canal seemed to communicate with the periodontal space. Taking all observations together, the condition was diagnosed as an ICR. Given that the pulp was vital and pain-free, the patient was advised to avoid further trauma in the region and to visit every two months for radiographic follow-up.

Despite the recommendations to return soon, the patient returned only 6 years after the first examination. Upon her new visit, another CBCT scan was performed using the same device and exposure parameters. Dynamic analysis of the axial, sagittal and coronal reconstructions

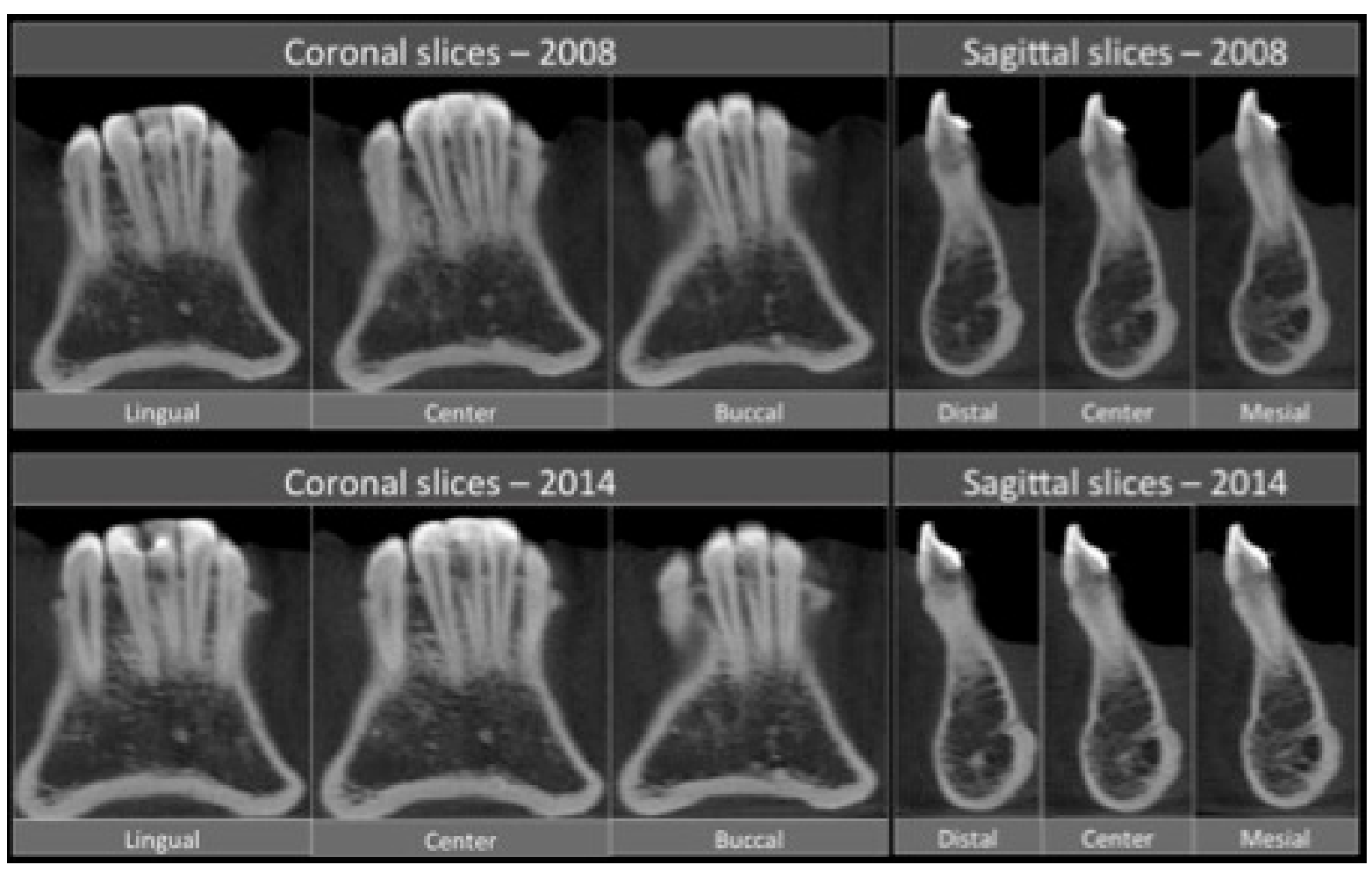

Figure 2. Cross sectional images, showing the real extent of the ICR lesion. Sequence of coronal and sagittal reconstructions acquired at the first visit and 6 years later suggested an increase of the lesion extent. 
suggested an increase of the lesion's extent, but clinical signs and symptoms remained absent (Fig. 2). The Fusion tool available on the OnDemand3D software (Cybermed, Seoul, Korea) was used to register the DICOM images from the first and the second visit, 6 years later. This tool allowed the selection of exactly the same region of interest without the operator's interference.

In addition, Regeemy (Image Registration and Mosaicking Software version 0.2.43-RCB, DPI-INPE, São José dos Campos, SP, Brazil) was also used to subtract the images and document the lesion's progress. Images were saved as TIFF and imported into Regeemy. This software equalized the contrast of 2 sequential images: the image taken at the first visit was selected as image 1 , and the image taken 6 later was selected as image 2 . Reference points were selected on both images, allowing the software to correct the geometry of the second image according to the first. The registration and the subtraction confirmed the lesion growth evidenced by the darkened regions at the distal and central portions of the tooth root (Fig. 3). After image registration and subtraction, the patient was referred for endodontic treatment.

\section{Discussion}

Traditionally, the diagnosis of internal root resorption and ICR has been limited by the unreliable information obtained from conventional radiography, both film-based and digital.

Conventional radiography does not accurately locate neither clarifies the nature of a resorptive defect; it is also unable to determine the thickness of the remaining dentine that protects the root canal, especially in the buccolingual aspect. Overlapping and image distortion are additional drawbacks that compromise the diagnostic accuracy of conventional radiographic techniques (11).

Through the application of CBCT in Dentistry, the subtleties of three-dimensional dentoalveolaranatomyare now within the reach of the general practitioner $(7,8,12,13)$. CBCT is used in Endodontics for assessment of root canal morphology, pathoses of non-endodontic origin and root fractures, as well as analysis of external and internal root resorption and pre-surgical planning $(12,14)$.

It is essential that patients exposed to conditions that may damage the periodontium undergo periodic clinical and radiographic examinations (15). There is evidence that orthodontic treatment alone was a predisposing factor in almost one out of four (24.1\%) teeth with ICR (15). The case reported here fits Heithersay's Class 3 definition, as the defect involved the coronal third of the root; also, the history of orthodontic treatment suggests a putative cause of the present condition.

Correct diagnosisand understanding of the etiopathology of tooth resorptionsare critical for the effective management of these conditions. Tooth resorptions can be classified as

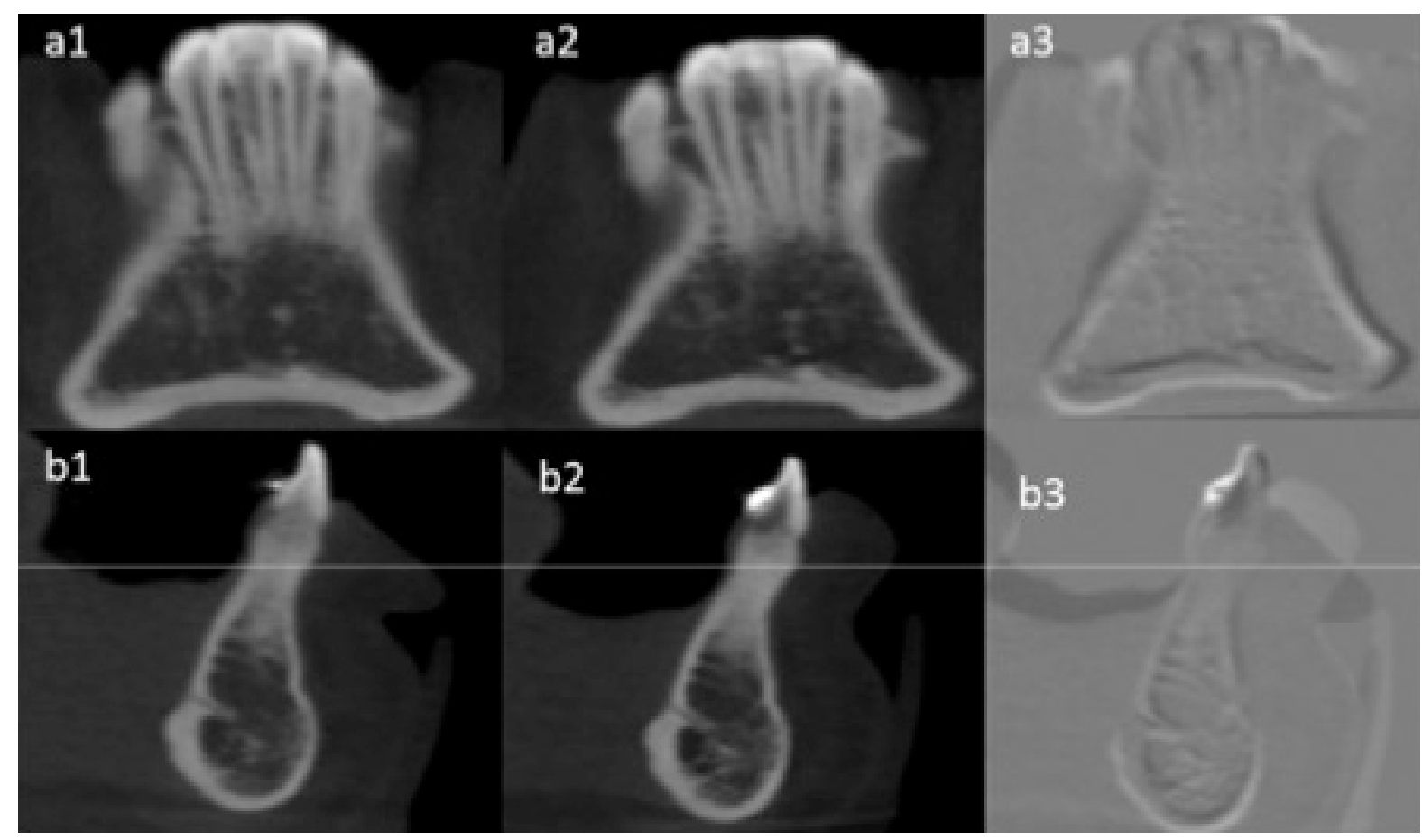

Figure 3. The Fusion tool was used to register the images: a1 coronal view (1st scan); a2 coronal view (2nd scan, 6 years later); b1 sagittal view (1st scan); b2 sagittal view (2nd scan, 6 years later). Image subtraction showing lesion progress appears as dark areas, meaning loss of mineral tissues. a3 is a coronal central view and b3 is a sagittal distal view. The white area in b3 is the resin in the lingual side, not related with the lesion. 
trauma- or infection-induced, or as hyperplastic invasive (2). Sometimes, transient trauma-induced resorption requires no treatment at all. Still, these cases must be carefully monitored to avoid complications like infection. In the case reported herein, the patient had completed orthodontic treatment but showed no clinical signs or symptoms. She was informed of the findings obtained from clinical, radiographic and tomographic examinations. Then, two options were presented: one, to undergo endodontic treatment or two, to visit periodically for radiographic monitoring, since the orthodontic trauma was nolonger present. Some authors suggest prophylactic endodontic treatment for traumatized teeth (16). However, the guidelines of the International Association of Dental Traumatology (IADT) recommend endodontic treatment only after pulp necrosis is confirmed clinically and radiographically (17). As our patient's tooth had a vital pulp and she had no clinical signs or symptoms, the choice was to defer endodontic treatment. Furthermore, endodontic treatment in such a frail tooth could be more detrimental than beneficial. Digital intraoral radiography is relatively accurate for the detection of ICR, but the superior accuracy of CBCT seems to favor the correct diagnosis and management of resorptive lesions $(11,13,18)$. Considering the limitations of a case report to provide scientific evidence, with this case report the main aim was to highlight post-processing tools available in some softwares. In the present case, the axial, sagittal and coronal reconstructions were fundamental to distinguish the ICR from internal root resorption and to determine the degree of tissue compromise (Heithersay's Class 3).

The effective radiation dose during CBCT image acquisition is higher than that of conventional intraoral radiography. Recent guidelines state that CBCT examinations are justifiable when the benefits outweigh the inherent risks of the higher radiation doses and when relevant new information can be gathered $(14,19)$. As previously discussed, the benefits achieved for this case were the establishment of a definitive diagnosis, as well as the decision to be conservative and to defer endodontic treatment. Periodical follow-up appointments are advised to allow for early detection of pulp necrosis or clinical symptoms that require endodontic and/or surgical intervention. It is important to emphasize, however, that routine CBCT imaging to follow ICR lesions is not justified unless a new risk/benefit assessment deems it so.

CBCT data were imported to the OnDemand3D software and the fusion technology was used. OnDemand3D's Fusion technology employs a basic concept from information theory- mutual information (MI) or relative entropy - as a matching criterion. Using $\mathrm{MI}$ in image superposition was first suggested for registration of $3 \mathrm{D} C \mathrm{CT}, \mathrm{MR}$ and
PET brain images of single objects (20). This tool allows for registration of DICOM data that may have been scanned at a different time or condition, or even with different equipment. The technology makes clearer the changes over time and may even rescue previously overlooked signs.

After registration, TIFF images were imported to Regeemy for image subtraction. The software automatically selects pixels of the same tone in the two images and superposesthem. Ono et al. (21) used Regeemy to evaluate and confirm the software's fitness in detecting simulated external root resorption (21). Another study showed that Regeemy is indeed appropriate for image superposition and subtraction (22). In the case reported here, the images obtained after subtraction were useful to show that the ICR lesion was growing, which was crucial for making the treatment decision - i.e., endodontic treatment. As the use of image subtraction for cases of ICR is not well established in the literature, further studies are required to provide robust scientific evidence regarding the issue reported herein.

This report illustrated the usefulness of CBCT imaging and its imaging post-processing tools in the differential diagnosis, management and follow-up of an ICR case. This three-dimensional imaging modality can delimit the extent of the ICR lesion and can identify possible sites of communication with the periodontal space; the fusion and subtraction tools also left no doubt with regards to the lesion progress.

\section{Resumo}

Com este relato de caso clínico objetiva-se enfatizar a contribuição das ferramentas de pós-processamento aplicadas às imagens de tomografia computadorizada de feixe cônico (TCFC) no diagnóstico, acompanhamento e decisão do tratamento de reabsorção cervical invasiva (ICR). Paciente do sexo feminino, com 16 anos de idade foi encaminhada para realização de radiografia periapical e foi observada radiolucência irregular, na raiz do incisivo central inferior direito. A TCFC foi realizada no intuito de se obter diagnóstico diferencial entre ICR e reabsorção radicular interna. Após o diagnóstico de ICR, o paciente foi orientado a retornar em breve, mas o fez somente seis anos mais tarde. Fez-se assim outra tomografia e registro e subtração foram realizados para documentar a progressão da lesão. Essas ferramentas foram capazes de revelar claramente o progresso da lesão, sua real extensão e foram fundamentais para o diagnóstico diferencial e decisão de tratamento.

\section{References}

1. Patel S, Ford TP. Is the resorption external or internal? Dent Update 2007;34:218-220.

2. Heithersay G. Invasive cervical resorption. Endod Top 2004;7:73-92.

3. Tronstad L. Root resorption - etiology, terminology and clinical manifestations. Endod Dent Traumatol 1988;4:241-252.

4. Heithersay GS. Clinical, radiologic and histopathologic features of invasive cervical resorption. Quintessence Int 1999;30:27-37.

5. Vasconcelos KF, Nejaim Y, Haiter Neto F, Boscolo FN. Diagnosis of invasive cervical resorption by using cone beam computed tomography: report of two cases. Braz Dent J 2012;23:602-607.

6. Kim E, Kim KD, Roh BD, Cho YS, Lee SJ. Computed tomography as a diagnostic aid for extracanal invasive resorption. J Endod 2003;29:463- 
465.

7. Marmulla R, Wortche R, Muhling J, Hassfeld S. Geometric accuracy of the NewTom 169000 Cone Beam CT. Dentomaxillofac Radiol 2005;34:28-31.

8. Sonick M, Abrahams J, Faiella RA. A comparison of the accuracy of periapical, panoramic, and computerized tomographic radiographs in locating the mandibular canal. Int J Oral Maxillofac Implants 1994;9:455-460.

9. Ziegler CM, Woertche R, Brief J, Hassfeld S. Clinical indications for digital volume tomography in oral and maxillofacial surgery. Dentomaxillofac Radiol 2002;31:126-130.

10. Mol A. Imaging methods in periodontology. Periodontology 2004;34:34-48

11. Patel $\mathrm{S}$, Dawood A. The use of cone beam computed tomography in the management of external cervical resorption lesions. Int Endod J 2007:40:730-737.

12. Cotton TP, Geisler TM, Holden DT, Schwartz SA, Schindler WG. Endodontic applications of cone-beam volumetric tomography. J Endod 2007;33:1121-1132.

13. Patel $S$, Kanagasingam $S$, Pitt Ford T. External cervical resorption: a review. J Endod 2009;35:616-625.

14. Patel $S$, Durack $C$, Abella F, Roig $M$, Shemesh $H$, Lambrechts $P$, et al. European Society of Endodontology position statement: the use of CBCT in endodontics. Int Endod J 2014;47:502-504.

15. Heithersay GS. Invasive cervical resorption: an analysis of potential predisposing factors. Quintessence Int 1999;30:83-95.

16. Wolner-Hanssen $A B$, von Arx $T$. Permanent teeth with horizontal root fractures after dental trauma. A retrospective study. Schweiz Monatsschr Zahnmed 2010;120:200-212.

17. Flores MT, Andersson L, Andreasen JO, Bakland LK, Malmgren B,

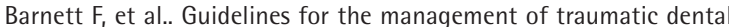
injuries. I. Fractures and luxations of permanent teeth. Dent Traumatol 2007;23:66-71

18. Cohenca N, Simon JH, Mathur A, Malfaz JM. Clinical indications for digital imaging in dento-alveolar trauma. Part 2: root resorption. Dent Traumatol 2007;23:105-113.

19. SEDENTEXCT. Radiation protection no. 172: cone beam CT for dental and maxillofacial radiology - evidence-based guidelines. 2012. Available from: http://www.sedentexct.eu/files/radiation_protection_172.pdf. Latest access August 4, 2016.

20. Maes F, Collignon A, Vandermeulen D, Marchal G, Suetens P. Multimodality image registration by maximization of mutual information. IEEE Trans Med Imaging 1997;16:187-198.

21. Ono E, Medici Filho E, Faig Leite $H$, Tanaka JL, Moraes ME, Melo Castilho JC. Evaluation of simulated external root resorptions with digital radiography and digital subtraction radiography. Am J Orthod Dentofacial Orthop 2011;139:324-333.

22. Giannastasio D, Rosa RA, Peres BU, Barreto MS, Dotto GN, Kuga MC, et al.. Wizard13CD Plus and ProTaper Universal: analysis of apical transportation using new software. J Appl Oral Sci 2013;21:468-474.

Received May 28, 2015

Accepted April 29, 2016 